\title{
A YAC contig in Xp21 containing the adrenal hypoplasia congenita and glycerol kinase deficiency genes
}

Ann P.Walker ${ }^{\star}$, Jamel Chelly, Donald R.Love ${ }^{1,+}$, Yumiko Ishikawa Brush, Dominique Récan², Jean-Louis Chaussain ${ }^{3}$, Christine A.Oley ${ }^{4, \S}$, J.Michael Connor ${ }^{5}$ John Yates $^{6}$, David A.Price ${ }^{7}$, Maurice Super ${ }^{7}$, Armand Bottani ${ }^{8,9}$, Beat Steinman ${ }^{8}$, Jean-Claude Kaplan ${ }^{2}$, Kay E.Davies ${ }^{1}$ and Anthony P.Monaco

ICRF Laboratories and 'Molecular Genetics Group, Institute of Molecular Medicine, John Radcliffe Hospital, Oxford OX3 9DU, UK, ${ }^{2}$ Laboratoire de Biochimie Génétique, Hôpital Cochin-Port Royal, 75014 Paris, ${ }^{3}$ Hôpital St Vincent de Paul, 75014 Paris, France, ${ }^{4}$ Mater Misericordiae Mother's Hospital, South Brisbane, Queensland 4101, Australia,

${ }^{5}$ Department of Medical Genetics, Duncan Guthrie Institute, Glasgow G3 8SJ, ${ }^{6}$ Department of Pathology, University of Cambridge, Cambridge CB2 1QP, ${ }^{7}$ Royal Manchester Children's Hospital, Pendlebury, Manchester M27 1HA, UK and

${ }^{8}$ Division of Metabolism, Department of Paediatrics, University Children's Hospital, Zurich, $\mathrm{CH}-8032$ Zurich, Switzerland

Received August 10, 1992; Revised and Accepted September 4, 1992

\begin{abstract}
The gene loci for adrenal hypoplasia congenita (AHC) and glycerol kinase deficiency (GK) map in Xp21 distal to Duchenne muscular dystrophy (DMD), and proximal to DXS28 (C7), by analysis of patient deletions. We have constructed a yeast artificial chromosome (YAC) contig encompassing a $1.2 \mathrm{Mb}$ region extending distally from $\mathrm{DMD}$, and containing DXS708 (JC-1), the distal junction clone of a patient with GK and DMD. A pulsed-field gel electrophoresis map of the YAC contig identified 3 potential CpG islands. Whole YAC hybridization identified cosmids both for construction of cosmid contigs, and isolation of single copy probes. Thirteen new single copy probes and DXS28 and DXS708 were hybridized on a panel of patients; the deletion mapping indicates that the YAC contig contains both GK and at least part of $\mathrm{AHC}$, and together with the physical map defines a GK critical region of 50-250 $\mathrm{kb}$. In one AHC patient with a cytogenetically detectable deletion we used the new probes to characterize a complex double deletion. Nonoverlapping deletions observed in other unrelated AHC patients indicate that the AHC gene is large, extending over at least $200-500 \mathrm{~kb}$. This mapping provides the basis for the identification of the AHC and GK genes.
\end{abstract}

\section{INTRODUCTION}

The Xp21 contiguous gene deletion syndrome of glycerol kinase deficiency (GK), adrenal hypoplasia congenita (AHC) and/or Duchenne muscular dystrophy (DMD) results from deletion of physically linked loci in chromosome band Xp21. Patients with $\mathrm{Xp} 21$ deletions will exhibit the combination of independent phenotypes corresponding to loss of individual critical genes in the deleted DNA segment. By cytogenetic and molecular analysis of patient deletions, the genes underlying AHC and GK have been positioned in Xp21.3-Xp21.2, between the $3^{\prime}$ end of the DMD locus and the distal group of probes L1-4 (DXS68) - B24 (DXS67) - C7 (DXS28), (1-13). This group of DNA probes had been described in conflicting orders when based on patient deletions $(1,12,14)$, and on genetic linkage data (15). However, the order Xpter-DXS68-DXS67-DXS28-Xcen is defined by three independent reports, involving: i) reanalysis of deletion data and analysis of a new informative deletion (16); ii) fluorescent in situ hybridization of interphase nuclei (17); and iii) YAC contig data (18), all in agreement with published pulsed-field gel electrophoresis (PFGE) studies on genomic DNA $(19,20)$. Thus the AHC and GK gene loci map in the region between DXS28 (C7) and the 3' end of the DMD gene. Until recently, just one probe had been accurately placed in this interval with respect to the published order: probe JC-1 (DXS708), the distal junction fragment of a patient with GK and DMD but not AHC (21). DXS708 therefore maps proximal to AHC, and either within or distal to GK. Long range PFGE studies revealed that JC-1 detects fragments of approximately $3.5 \mathrm{Mb}$ and $4.2 \mathrm{Mb}$ in partial $\mathrm{BssH}$ II digests from a 48, XXXX cell line; these large fragments are not detected by DXS28 (C7), or by DXS268 (J66) in the 3' end of the DMD gene (21). Thus the interval containing the AHC and GK genes is indicated to be at least $4 \mathrm{Mb}$ in size. More recently, two new probes YHX39 (DXS727) and QST59 (DXS319) have been placed in this large interval, and a third probe FT1 (DXS726) has been mapped within $10 \mathrm{~kb}$ of the $3^{\prime}$ end of the DMD gene. (22). Both DXS727 and DXS319 were deleted in a patient with AHC only, indicating that they are distal to GK and close to the AHC locus. An additional patient with AHC, GK and DMD was found to have DXS28 and DXS727 present, but DXS319 absent, defining the order of these new probes as Xpter-DXS28-DXS727-DXS319-DXS726-DMD-Xcen (22).

\footnotetext{
* To whom correspondence should be addressed
}

Present addresses: ${ }^{+}$CRC Human Cancer Genetics Research Group, Department of Pathology, University of Cambridge, Cambridge CB2 IQP, ${ }^{5}$ Northern Region Genetics Service, Royal Victoria Infirmary, Newcastle upon Tyne NE2 4AA, UK and 'Division de Génétique Médicale, Centre Medical Universitaire, CH 1211 Geneve 4, Switzerland 
Alu-3144

Alu-3143

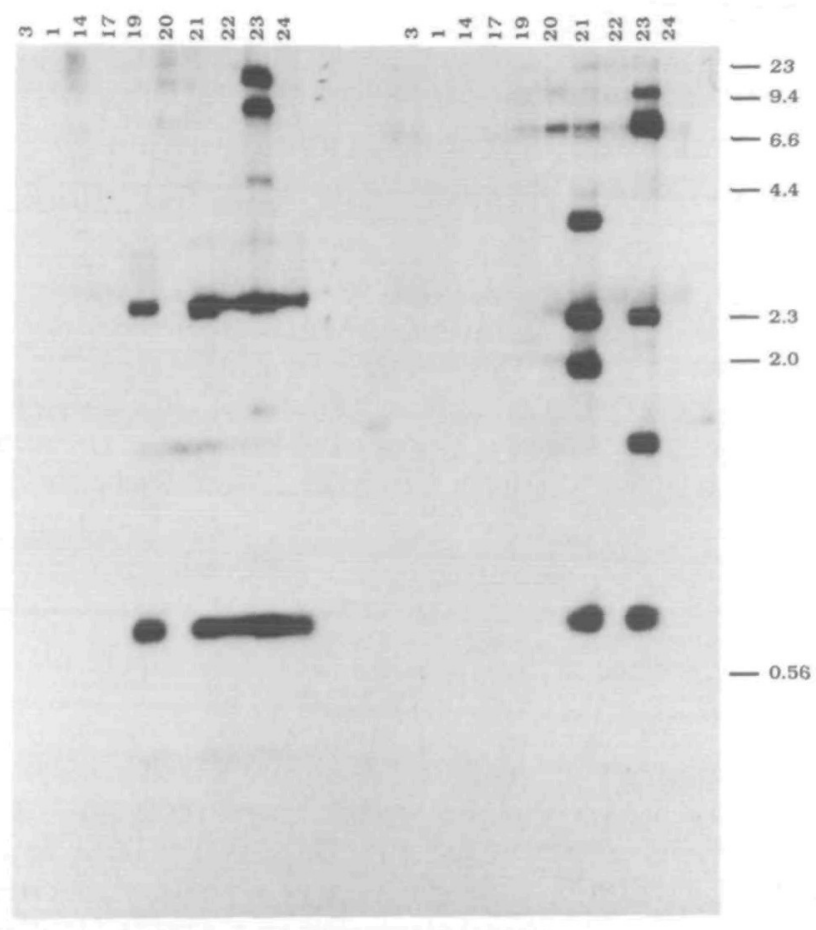

Figure 1. Hybridization of Alu PCR pools on the panel of $3^{\prime}$-DMD YACs. Alu PCR pools were amplified from DMD YAC $3^{\prime}-23$ using either primer 3144 or 3143 , and hybridized to Hind III digests of $3^{\prime}$-DMD YACs (24). The YACs are numbered above each lane as previously designated (24). Lambda/Hind III markers are indicated (sizes in kb). The Alu 3143 pool detected 2 fragments in YAC 3'-21 (24) not seen in the cognate YAC, $3^{\prime}-23$. One of these was the junction fragment of YAC $3^{\prime}-21$ with the left vector arm; the second may result from a previously undetected chimeric insert or rearrangement of YAC $3^{\prime}-21$, or a polymorphism.

We have employed a large insert YAC library (23) to link physically the 3' end of DMD to DXS708 (JC-1). Cosmid, phage, plasmid and Alu-PCR probes derived from the YACs have been used to construct a physical map. Hybridization of 13 new single copy probes and DXS28 and DXS708 to a panel of 20 patient DNA samples indicates that the YAC contig contains the whole of the GK gene, and also at least part of the AHC gene. The physical map and deletion results together define mapping intervals for these genes.

\section{RESULTS}

\section{Mapping of Alu repeat primed PCR probes}

The most distal YAC of the previously described 3.2 Mb DMD YAC contig (24) was DMD 3'-23 $(890 \mathrm{~kb})$, which we demonstrate contains both the $3^{\prime}$ end of the DMD gene and DXS708 (JC-1), and therefore must contain at least part of the GK gene. Two pools of Alu PCR products were amplified from $3^{\prime}-23$ using two independent primers, 3143 and 3144 (see Methods). Each pool was mapped by hybridization to Hind III digests of the 10 most distal YACs of the DMD contig (24), spanning and extending beyond the ${ }^{\prime}$ ' end of the DMD gene (Figure 1). The Alu 3144 pool of PCR products identified strongly hybridizing bands in the cognate YAC DMD 3 '-23, plus
Table 1. Mapping of cosmid clones identified with YAC DMD 3'-23.

\begin{tabular}{|c|c|c|c|c|c|}
\hline $\begin{array}{l}\text { Cosmid } \\
\text { no. }\end{array}$ & $\begin{array}{l}\text { YAC } \\
7023\end{array}$ & $\begin{array}{l}\text { Alu- } \\
3143\end{array}$ & $\begin{array}{l}\text { Alu. } \\
3144\end{array}$ & $\begin{array}{l}\text { DMD } \\
63-1\end{array}$ & $\begin{array}{l}\text { RC enzyme } \\
\text { sites }\end{array}$ \\
\hline $\begin{array}{l}1 \\
2 \\
4 \\
5 . \\
6 \\
7 \\
8 . \\
9 \\
11^{\circ} . \\
13^{\circ} \\
14 \\
18 \\
22^{\circ} \\
23 \\
24 \\
25^{\circ} \\
26 \\
27 \\
28 \\
29 \\
30^{\circ} \\
31^{\circ} \\
32 \\
33 \\
34^{\circ} \\
36 \\
37 \\
38^{\circ} \\
39\end{array}$ & + & + & + & + & $\begin{array}{l}n t \\
n t \\
n t \\
\cdot \\
n t \\
n t \\
E \\
B, E \\
n t \\
B, E \\
n t \\
n t \\
B \\
n t \\
n t \\
2 B, 2 E \\
- \\
n t \\
2 B, E, N \cdot \\
- \\
- \\
n t \\
B \\
E \\
2 B, E, N \cdot \\
n t \\
B, E \\
- \\
E\end{array}$ \\
\hline
\end{tabular}

The 29 viable cosmids which contained genomic inserts are listed. + denotes hybridization of the indicated probe with the cosmid DNA spot on the ICRF flow sorted human chromosome $\mathrm{X}$ gridded cosmid library filters. Rare curting (RC) enzyme sites are: B, BssH II; E, Eag I; N, Not I; - , none of these sites; nt, not tested. *denotes cosmid selected for isolation of unique subclones; ${ }^{*}$ identifies the 2 overlapping cosmids containing a Not I site. Twenty three of these 29 cosmids (79\%) have been tested and confirmed to map back to YAC 3'-23.

4 other YACs: $3^{\prime}-19,21,22$ and 24 , but did not identify the DMD region control YACs, $3^{\prime}-20$ and $3^{\prime}-17$. From the physical map of the DMD contig (24), these Alu 3144 products map distal to DMD within the region approximately $250-450 \mathrm{~kb}$ from the proximal (DMD) end of the YAC. In contrast, the Alu 3143 pool detected strongly hybridizing bands in the cognate YAC $3^{\prime}-23$ and $3^{\prime}-21$, these being two of the three YACs extending furthest distally from the DMD gene. The third YAC, $3^{\prime}-22$, did not hybridize due to a probable distal chimeric insert. The Alu 3143 pool of PCR products was therefore identified as mapping in the distal $500 \mathrm{~kb}$ of YAC 3'-23. The two pools of Alu PCR products were used in mapping the cosmids, identified by whole YAC hybridization, so that cosmids spanning the length of $3^{\prime}-23$ were chosen for subcloning.

\section{Chacterization of cosmids and isolation of probes}

Hybridization of YAC DMD $3^{\prime}-23$ to approximately 3-4 chromosome equivalents of the ICRF flow sorted human chromosome X gridded cosmid library (25) identified 39 positives. They were mapped regionally within YAC $3^{\prime}-23$ by hybridizing the cosmid filters with Alu PCR pools 3143 and 3144 , DMD cDNA 63-1, and the newly isolated JC-1 YAC 7023 (400 $\mathrm{kb})$. Of the 39 original positives, 5 never grew from the frozen glycerol stock, and 5 were deduced to contain nonrecombinant polyvector inserts, by hybridization with Bluescript (Stratagene). Hybridization results of the gridded cosmid library filters are 


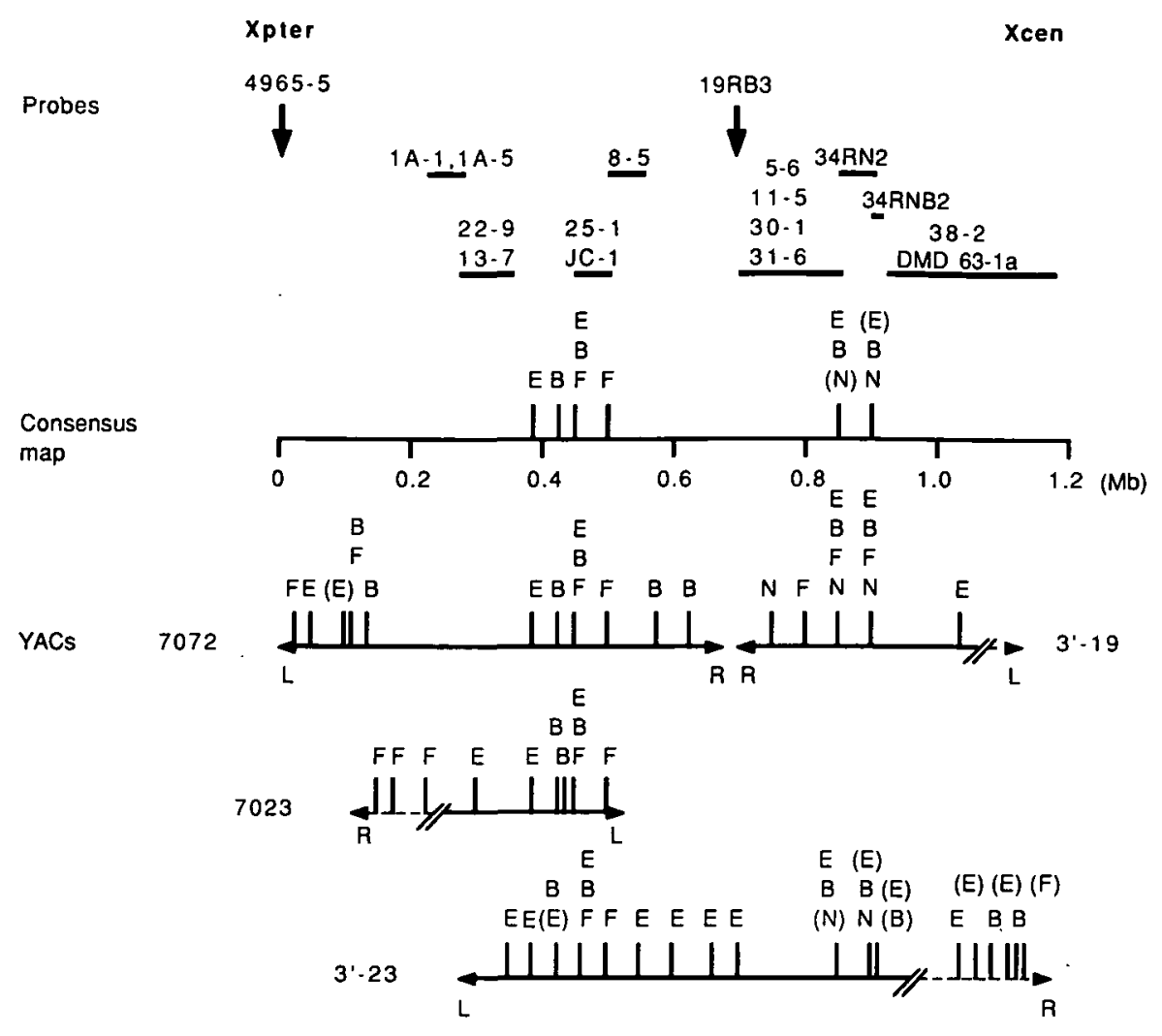

Figure 2. A $1.2 \mathrm{Mb}$ YAC contig and physical map localizing probes in the AHC-GK region. The lower part of the figure shows physical maps of individual YACs 7072, 7023, DMD 3'-23 and 3'-19, as determined by partial digestion mapping with Sfi I, F; Not I, N; BssH II, B; and Eag I, E. Sites exhibiting partial digestion in YACs are shown in brackets, (). A double slash across the YAC indicates the probable position of a chimeric junction; a dashed lines indicates the portion of chimeric YACs that is not colinear with this Xp21 region. Three potential CpG islands were observed; these and other rare cutting enzyme sites observed consistently are positioned in the centre of the figure (scale in $\mathrm{Mb}$ ), on the consensus map. Sites observed only in one YAC are marked only on that YAC (see Discussion). At the top of the figure, 15 new subclones plus JC-1 and DMD 63-1a are mapped according to their hybridization to pulsed-field gel electrophoresis fragments. The primary data path supporting the mapping of these probes is available on request from the authors. The positions of 19RB3, the subclone isolated from the right end phage from DMD YAC 3'-19, and 4965-5, the subclone isolated from the left end cosmid of YAC 7072, are indicated by arrows, as defined by the position of these YACs in the contig. Probes $1 \mathrm{~A}-1$ and $1 \mathrm{~A}-5$ could be ordered as shown because they mapped on either side of the chimeric junction of the YAC 7023 insert. D numbers have been assigned to one probe from each cosmid contig distal to the DMD locus : 4965-5 (DXS1074); 1A-1 (DXS1075); 13-7 (DXS1076); 25-1 (DXS1077); 8-5 (DXS1078); 19RB3 (DXS1079); 30-1 (DXS1080); 34R1 (DXS1081)

given in Table 1 for the remaining 29 viable cosmids. YAC JC-1 7023 identified 5 cosmids in common with YAC $3^{\prime}-23$ (cosmids $8,13,22,25$ and 39 ), representing the most distal cosmids within YAC $3^{\prime}-23$, and 1 new cosmid (7023-1A, not tabulated), distal to YAC DMD 3'-23. All cosmids detected with the DMD $3^{\prime}-23$ Alu PCR pools had been previously identified as positive with the DMD 3'-23 whole YAC hybridization. Three cosmids were detected with the Alu 3143 pool (cosmids 8, 25 and 37), and of these, two also hybridized with YAC 7023 (cosmids 8 and $25)$. A total of 5 cosmids $(5,11,18,27$ and 31) were detected with the Alu 3144 pool, and 6 independent cosmids $(1,4,6$, 23,36 and 38) were detected with DMD cDNA 63-1, representing the most proximal cosmids within YAC $3^{\prime}-23$.

Some cosmids were additionally characterized by digestion with Hind III alone and in double digests with the rare-cutting enzymes Not I, BssH II and Eag I. Two overlapping cosmids contained a Not I site (cosmids 28 and 34); one of these (cosmid 34), plus 9 cosmids spanning the length of YAC DMD 3'-23 (cosmids 5 , $8,11,13,22,25,30,31$ and 38; Table 1), and the single cosmid unique to YAC 7023 (cosmid 7023-1A), were selected for isolation of single copy probes. The right (distal) end of DMD YAC 3'-19 was isolated as a phage clone, and a probe (19RB3) was isolated from it as a unique subclone. A probe was also isolated from a cosmid (4965) identified by the vectorette PCR product amplified from the left (distal) end of the $660 \mathrm{~kb} \mathrm{JC}-1$ YAC 7072, representing the most distal extent of the YAC contig.

\section{Physical map of the YAC contig}

The newly isolated JC-1 YACs 7072 and 7023, and distal YACs from the 3.2 Mb DMD contig (24), 3'-23 and $3^{\prime}-19$, were subjected to partial digestion with Sfi I, Not I, BssH II and Eag I, and mapped by PFGE (Figure 2). Three potential CpG islands, containing 3 or more rare cutting enzyme sites, were observed: one immediately distal to JC-1, and two separated by $50 \mathrm{~kb}$, approximately $30 \mathrm{~kb}$ distal to the PFGE fragment hybridizing with the $3^{\prime}$ end of the DMD gene. These CpG islands and other rare cutting enzyme sites observed consistently in all YACs spanning a particular site were used to construct a consensus physical map of the contig. This defined the maximum extent of the contig from $3^{\prime}-19$ to 7072 as $1.2 \mathrm{Mb}$, extending the 3.2 Mb DMD contig (24) to $3.5 \mathrm{Mb}$. Some sites were observed only in one YAC, and these are shown in Figure 2 only on that YAC (see Discussion). 
Table 2. Deletion results for AHC-GK patients

\begin{tabular}{|c|c|c|c|c|c|c|c|c|c|c|c|c|c|c|c|c|c|c|c|}
\hline \multirow[t]{2}{*}{ PATIENT } & \multicolumn{3}{|c|}{ PHENOTYPE } & \multirow[t]{2}{*}{ REP } & \multicolumn{11}{|c|}{ PROBE } & \multirow[b]{2}{*}{1115} & \multirow[b]{2}{*}{$30 \sim 1$} & \multirow[b]{2}{*}{$34 R 1-1$} & \multirow[b]{2}{*}{$38-2$} \\
\hline & AHC & $G$ & DMD & & C7 & 4865-5 & 1A-1 & 1A-6 & $13-7^{\circ}$ & $22-9$ & $25-1$ & $\mathrm{JC}-1$ & $8-5$ & |19RB3 & $5 \sim 6$ & & & & \\
\hline AM & + & $\cdot$ & . & 7 & 0 & \begin{tabular}{|l|}
0 \\
\end{tabular} & + & + & + & + & + & + & + & + & + & + & + & + & + \\
\hline $\mathbf{\omega}$ & + & - & $\therefore$ & & + & + & 0 & 0 & + & + & + & + & + & + & + & + & + & + & + \\
\hline BEN & + & + & . & 27 & + & 0 & 0 & 0 & + & + & 0 & 0 & 0 & + & + & + & + & + & + \\
\hline$\Lambda S$ & + & + & - & & + & 0 & 0 & 0 & 0 & 0 & 0 & 0 & 0 & + & + & + & + & + & + \\
\hline$M C$ & + & + & - & & + & + & + & + & + & + & 0 & 0 & 0 & + & + & + & + & + & + \\
\hline $\mathrm{CC} \propto \mathrm{JH} t$ & + & + & - & & 0 & $\mathbf{0}$ & 0 & 0 & 0 & 0 & 0 & 0 & 0 & + & + & + & + & + & + \\
\hline $1477(\mathrm{JC})$ & - & + & + & 10.21 & + & + & + & + & + & + & + & $J$ & 0 & 0 & 0 & 0 & 0 & 0 & 0 \\
\hline $4482 \& 44836$ & + & + & + & 28 & + & 0 & 0 & 0 & 0 & 0 & 0 & 0 & 0 & 0 & 0 & 0 & 0 & 0 & + \\
\hline 1290 & + & + & + & 4.10 & + & 0 & 0 & 0 & 0 & 0 & 0 & 0 & 0 & 0 & 0 & 0 & 0 & 0 & 0 \\
\hline $\mathrm{M}$ & + & + & + & 8 & + & 0 & 0 & 0 & 0 & 0 & 0 & 0 & 0 & 0 & 0 & 0 & 0 & 0 & 0 \\
\hline 346 & + & + & + & $4,10,30$ & 0 & 0 & 0 & 0 & 0 & 0 & 0 & 0 & 0 & 0 & 0 & 0 & 0 & 0 & 0 \\
\hline$A B$ & + & + & + & 28 & 0 & 0 & 0 & 0 & 0 & 0 & 0 & 0 & 0 & 0 & 0 & 0 & 0 & 0 & 0 \\
\hline
\end{tabular}

Deletion results are shown for $\mathrm{C} 7, \mathrm{JC}-\mathrm{I}$ and $\mathrm{I} 3$ new probes on Hind III digested patient DNA. For phenotype, + and - indicate presence and absence of the disease phenotype, respectively. Where available, patient literature references are cited (REF). Six patients were not deleted for any of the probes tested: patients SO, ST, $\mathrm{SL}, \mathrm{BF}$ and EK (AHC only), and DK (GK only). For probe results, + and o indicate presence and deletion in patient DNA, respectively; J, junction fragment. The order of probes in the table is Xpter-Xcen, except that the orders of 13-7/22-9 and of 5-6/11-5/30-1 could not be determined. *, 13-7 detects a Hind III polymorphism; $t$, patients CC and $\mathrm{JH}$ are cousins; \#, patients 4482 and 4483 are brothers.

Fourteen new subclones plus JC-1 and DMD 63-1a were mapped according to their hybridization to PFGE fragments (Figure 2). D numbers have been assigned to one probe from each cosmid contig distal to the DMD locus (see the legend to Figure 2).

\section{Deletion mapping}

The patients with deletions are listed in Table 2, with their disease phenotype $(4,7,8,10,21,27-30)$ and hybridization results for $\mathrm{C} 7, \mathrm{JC}-1$ and the new subclones. Four new deletions were detected which would not have been seen with $C 7$ and DMD probes. A deletion was detected in all $(5 / 5)$ unrelated patients with the phenotype AHC-GK-DMD, in all (3/3) unrelated patients with AHC-GK, and in the single patient with GK-DMD. In contrast, a deletion was detected in $2 / 7$ (29\%) of unrelated patients with isolated AHC; no deletion has yet been detected in the single patient with isolated GK.

Patient BEN was observed to have a complex double deletion: a distal deletion encompassing 4965-5, $1 \mathrm{~A}-1$ and $1 \mathrm{~A}-5$ and a second proximal deletion encompassing 25-1, JC-1 and 8-5 (Figure 3). DXS28 was not deleted. The double deletion mapping was confirmed on 3 separate blots. Further probes will need to be isolated between $\mathrm{C7}$ and 4965-5 in order to map the distal deletion breakpoint accurately. The distal and proximal deletions are separated by $60-230 \mathrm{~kb}$ of DNA, and the proximal deletion spans $50-100 \mathrm{~kb}$. Non-overlapping deletions were observed in other unrelated AHC patients (AM, GJ versus MC; Figure 3), indicating that the $\mathrm{AHC}$ gene is large, extending at least between $4965-5 / 1 \mathrm{~A}-1$ and $25-1$, a region of $200-500 \mathrm{~kb}$.

A minimum mapping interval is defined by patient deletions to contain at least part of the GK gene. This GK critical region is defined distally by patient 1477 (JC), and proximally by BEN, $\mathrm{AS}, \mathrm{MC}, \mathrm{CC}$ and JH (Figure 3). The GK critical region therefore extends from JC-1 to 8-5/19RB3, a region of $50-250 \mathrm{~kb}$.

Probe 13-7 (DXS1076) was found to detect a frequent Hind III polymorphism (alleles $2.6 \mathrm{~kb}$ (frequency 0.47 ) and $0.9 \mathrm{~kb}$ (0.53), $57 \mathrm{X}$ chromosomes tested). Figure 4 illustrates hybridization of probes 13-7 and 8-5 together on Hind IIII digests of normal controls and patient DNA, showing the 13-7 polymorphism. Mendelian segregation of the 13-7 alleles through a 3-generation $\mathrm{AHC}$ family was observed (11 individuals tested), so that 13-7 can be used for concurrent analysis of deletions and polymorphism in AHC families, and as a distal flanking marker for DMD.

\section{DISCUSSION}

\section{Physical map of the AHC-GK region}

The $890 \mathrm{~kb}$ YAC DMD 3'-23 was observed to contain DMD Hind III exon-containing fragments and DXS708 (JC-1), demonstrating physical linkage of these two loci for the first time. This physical linkage of loci is consistent with the observation that some GK patients have deletions of the DMD gene $(8,9$, 11). JC-1 mapped on the $50 \mathrm{~kb}$ Sfi I fragment between the potential $\mathrm{CpG}$ islands located at $900 \mathrm{~kb}$ and $850 \mathrm{~kb}$ of the consensus map (Figure 2), corresponding to Sfi I sites $\mathbf{J}$ and $\mathbf{J}^{\prime}$ of the long range physical map $(24,26)$. This is in agreement with studies on genomic DNA, where JC-1 was observed on a Sfi I fragment of approximately $80 \mathrm{~kb}(21)$.

Three potential $\mathrm{CpG}$ islands were observed in the YACs. More rare cutting enzyme sites are observed in hypomethylated YAC DNA propagated in yeast than in human genomic DNA. The relationship of sites seen in YACs and in genomic DNA remains to be fully elucidated; however, the Sfi I sites J, J' and the site at $500 \mathrm{~kb}$ of the YAC consensus map are in agreement with published data on sperm and leukocyte DNA $(21,26)$. Preliminary data indicates that in DNA from a $48, \mathrm{XXXX}$ lymphoblastoid cell line, at least the CpG island at $900 \mathrm{~kb}$ of the consensus map is partially digested (unpublished observations). These $\mathrm{CpG}$ islands therefore represent candidate regions to search for potential $5^{\prime}$ coding sequences (31), in order to identify the AHC and GK genes.

A number of discrepancies were observed in the detection of rare cutting enzyme sites in overlapping YACs. Possible explanations for these discrepancies iñclude chimeric YAC inserts or rearrangement events, polymorphisms, and the reproducibility of partial digestion of rare-cutting enzymes on large YACs. The regions showing such inconsistencies were the proximal (right arm) $200 \mathrm{~kb}$ of $3^{\prime}-23$; possibly a very small $(<50 \mathrm{~kb})$ chimeric or rearranged insert at the proximal end of $3^{\prime}-19$, which shows 


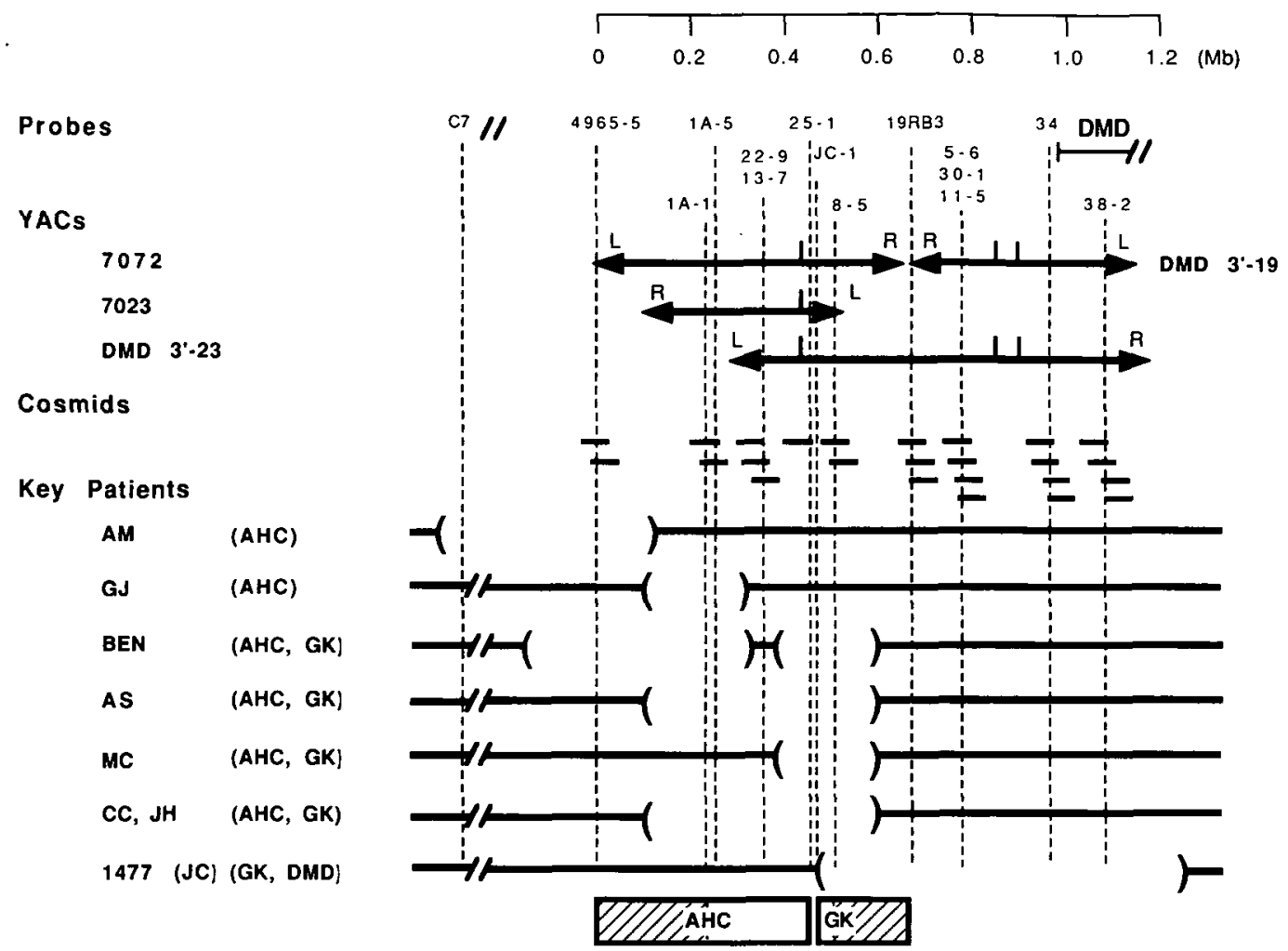

Figure 3. Map of AHC and GK critical regions. At the top of the figure are shown the positions of probes spanning the AHC-GK region, and the YAC contig, with the 3 potential CpG islands marked on the YACs as vertical bars. The distance between probes C7 and 4965-5 is not to scale. Beneath this are the cosmid contigs constructed around each probe. In the lower part of the figure, key patient deletions define critical regions for AHC and GK. A solid line indicates DNA which is present; brackets flanking an interruption in this line represent the deletion. The GK critical region is defined distally by patient 1477 (JC), and proximally by BEN, AS, MC, CC and JH. The GK critical region extends from JC-1 to 8-5/19RB3, a region of 50-250 kb. Patient BEN (AHC,GK) was observed to have a complex double deletion: a distal deletion encompassing 4965-5, 1A-1 and 1A-5 and a second proximal deletion encompassing 25-1, JC-1 and 8-5. DXS28 was not deleted. Non-overlapping deletions were observed in other unrelated AHC patients (AM, GJ versus MC), indicating that the AHC gene is large, extending at least between 4965-5/A1-1 and 25-1, a region of 200-500 kb. The AHC and GK critical regions as defined by patient deletions are shown as boxes. The portion of the critical region which must contain part of the gene is unshaded; the portion which may contain part of the gene, as defined by deletions, is shaded.

2 different Hind III fragments hybridizing with the left vector arm probe; and the distal $170 \mathrm{~kb}$ of 7023 . These possible chimeric YAC inserts do not detract from the consistent region bounded by probes $1 \mathrm{~A}-5$ and $38-2$, and verified in this region by both probe hybridizations confirmed across at least 2 YACs, and by consistent features of the consensus physical map across at least 2 YACs. The distal (right) end of 3'-19, and the distal (left) end of 7072, have both been confirmed as non-chimeric, by mapping the end clones back onto the YAC and cosmid contigs, and mapping on deletions in DNA from patients. Thus YACs from the contig are shown to span the entire region from 4965-5 to . 38-2; earlier work shows the contig extends further proximally to DMD Hind III exon containing fragment 53 (24).

\section{Complex deletion of patient BEN}

Patient BEN (AHC, GK) and his mother have an interstitial deletion involving. Xp21.2 and possibly Xp21.3, detected on prometaphase chromosomes (27): The chíromosomal deletion was found only upon high resolution chromosome banding. No molecular deletion was detected after hybridization of 11 probes from Xp21.2, including the DMD locus (27). Here we detected the proband's deletion at the molecular level using the new

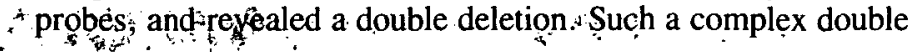

deletion has been described previously in a DMD family, where 2 brothers, 1 affected and 1 unaffected, and their mother, displayed deletion of DMD intron 7 probes $\mathrm{XJ} 10.1$ and $\mathrm{XJ} 1.1$ (DXS208). Only the affected brother displayed a second deletion detected with DMD cDNA 44-1 (32). It was proposed that the DXS208 deletion in one of the mother's X chromosomes may have contributed to the second unique deletion in the affected DMD male. A double deletion and translocation has also been reported on the $\mathrm{Y}$ chromosome (33), and 2 deletions separated by a $>110$ bp inversion have been characterized in the Xq28 $\mathrm{red} /$ green colour pigment gene in an adrenoleukodystrophy patient (34). It will be interesting to characterize the deletion in the mother of AHC-GK proband BEN at the molecular level. Certainly the origin of such double deletion events may be complex.

\section{The GK critical region}

The DNA of patient 1477 (JC) was used as a reference, by which probes could be mapped relative to the distal deletion breakpoint, isolated as probe JC-1 (DXS708). The proximal breakpoint of this deletion has been mapped between exons 42 and 43 (Hind III fragments 30 and 31) (21), within the DMD gene. Therefore, probes derived from YAC $3^{\prime}-23$ which are deleted in the DNA 


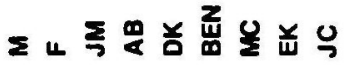

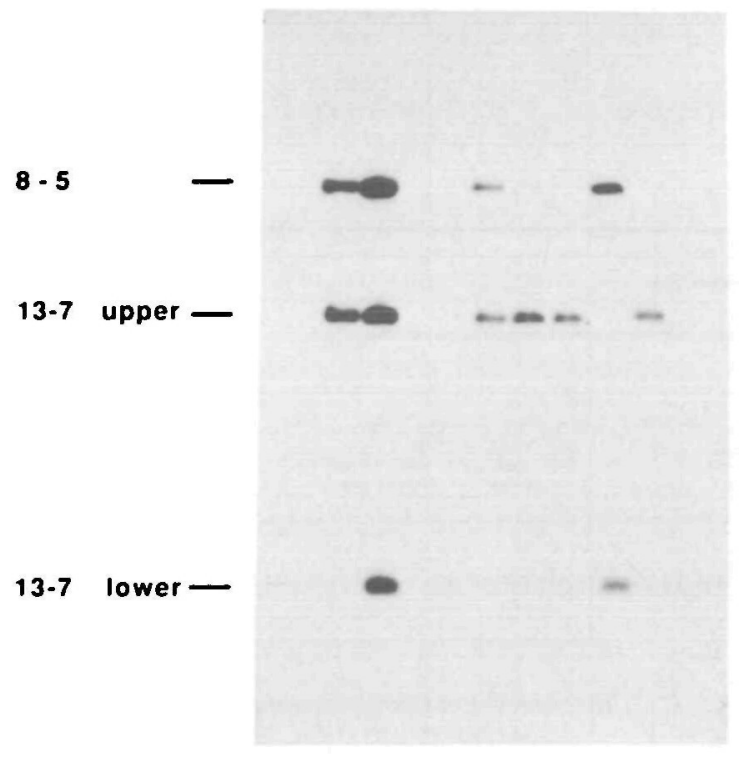

Figure 4. Hybridization of probes 8-5 and 13-7 to Hind III digests of control and patient DNA. Hind III digested DNA from a normal male (M) and normal female $(\mathrm{F} ; 10 \mu \mathrm{g})$, and from a subset of the patients listed in Table $2(5 \mu \mathrm{g})$, were hybridized with pooled probes 8-5 and 13-7. Probe 8-5 detects a constant band at $4.5 \mathrm{~kb}$. The polymorphic probe 13-7 detects alleles of 2.6 and $0.9 \mathrm{~kb}$. Deletions are demonstrated in patients JM, AB, BEN, MC and JC (1477); the latter deletion maps 8-5 proximal and 13-7 distal to the distal deletion breakpoint of patient JC (1477) (DXS708, JC-1).

of patient 1477 are proximal to JC-1; if present, the probe must be distal to JC-1 (Figure 3). This allowed 25-1 to be localized distal to JC-1 (Table 2); these probes could not be resolved by PFGE mapping (Figure 2).

The AHC and GK genes were previously known to flank DXS708, and were localized within a genomic region of $4 \mathrm{Mb}$. The patient deletions and physical map described here permit more accurate localization of a critical region for each gene, defined as the minimum region which must contain at least part of the gene. This will allow targeting of subsequent searches for coding sequence to those regions known to contain exons. The GK critical region is flanked distally by JC-1 and proximally by $8-5 / 19 R B 3$, a region of $50-250 \mathrm{~kb}$.

\section{Extent of the AHC gene}

Deletions were detected in all 9 independent patients with a complex phenotype of at least 2 diseases, reflecting the presence of relatively large deletions (Table 2). In contrast, a deletion was detected in only $2 / 7$ independent patients with a single disease, either GK or AHC. This low frequency of deletion detection in patients with a single disease may result from small gene deletions, possibly removing only part of the gene, or from point mutations. In the case of AHC, it is also possible that the gene may extend further distally beyond our most telomeric probe; isolation of further distal probes will be important to investigate this possibility.

Non-overlapping deletions were observed in unrelated AHC patients, indicating that the AHC gene is large, extending over at least $200-500 \mathrm{~kb}$. The finding of non-overlapping deletions in unrelated DMD patients was an early indication that the DMD gene is large (35). The complete DMD gene has now been mapped by PFGE to span approximately $2400 \mathrm{~kb}(14,19,20$, $26,30,36-38$ ). The AHC gene is located between DXS28 (C7) and $25-1$, a region estimated at approximately $3000 \mathrm{~kb}$. Isolation and mapping of new probes in the interval between $\mathrm{C} 7$ and 4965-5 will be important to test AHC patients for distal deletions.

The map presented here provides the basis to identify the genes for $\mathrm{AHC}$ and GK, by characterization of $\mathrm{CpG}$ island regions, and by searching for coding sequence within the defined critical regions. In this hunt for exons, sequence analysis, cross-species hybridization using both single copy and whole cosmid probes, and exon amplification procedures (39) should lead ultimately to the identification and cloning of the GK and AHC genes.

\section{MATERIALS AND METHODS}

\section{YAC library screening and YAC DNA preparation}

The ICRF Human YAC Reference Library was screened with probe JC-1 (DXS708) (21) by colony hybridization (23). Positive yeast clones were streaked onto selective agar plates (-uracil, -tryptophan). Isolated colonies were inoculated into selective medium (-uracil, -tryptophan) for preparation of chromosomes in agarose blocks $(23,40)$.

\section{Alu repeat primed PCR probes}

YAC DMD 3'-23 (24) was used as template for Alu repeat primed PCR, using either $5^{\prime}$ Alu primer 3143 (H.Lehrach, unpublished) or 3' Alu primer 3144 (41). Approximately $100-200 \mathrm{ng}$ total DNA was amplified using reaction conditions as described (41). PCR products were analysed on ethidium bromide stained $1 \%$ agarose, $1 \%$ NuSieve (F.M.C.) gels and shown to contain 3 to 4 products, ranging from 0.3 to $2 \mathrm{~kb}$. No amplification was observed from yeast DNA template or from no DNA controls. The pools of Alu PCR products were separated from Alu primers over Qiagen (Hybaid) columns, and approximately 50 ng DNA was radioactively labelled (42). The labelled Alu PCR products were denatured and preannealed by addition of sheared total human DNA (Sigma) to $2.5 \mathrm{mg} / \mathrm{ml}$, and SSC to $5 \times$ denaturation at $100^{\circ} \mathrm{C}$ for $10 \mathrm{~min}$, ice for $1 \mathrm{~min}$, and incubation at $65^{\circ} \mathrm{C}$ for $120 \mathrm{~min}$ (Cot $=300 \mathrm{mg} \cdot \mathrm{min} / \mathrm{ml}$ ). The preannealed probes were hybridized to Hind III digests of YACs and to the ICRF flow sorted human chromosome $\mathrm{X}$ cosmid reference library (25). The filters were incubated for 18 $\mathrm{h}$ in prehybridization solution (23) plus $100 \mu \mathrm{g} / \mathrm{ml}$ sheared total human DNA, and hybridized with labelled Alu PCR fragments in the same solution without human DNA. Blots were washed twice for $30 \mathrm{~min}$ in $4 \times$ SSC at room temperature, and twice for $30 \mathrm{~min}$ in $0.1 \times \mathrm{SSC}, 1 \% \mathrm{SDS}$ at $65^{\circ} \mathrm{C}$, and exposed to X-ray film for $1-4$ days at $-70^{\circ} \mathrm{C}$.

\section{Whole YAC screening of cosmid library}

DMD 3'-23 and JC-1 7023 YAC DNAs were purified from yeast chromosomes on $1.1 \%$ SeaPlaque (F.M.C.) low melt agarose, $0.5 \times$ TBE gels, under appropriate PFGE conditions. The gels were stained with ethidium bromide, and the YAC DNA band was excised under long wave U.V. light. Agarose was removed by digestion with agarase (Sigma) according to the supplier's protocol, followed by phenol-chloroform extraction and ethanol precipitation. Whole YAC probes were labelled and hybridized to cosmid library filters (43).

\section{Subcloning of cosmids}

Cosmids were digested with Hind III, subcloned into Hind III digested and phosphatased Bluescript, and transformed into competent XL1-Blue cells (Stratagene). Fragments not hybridizing with total human genomic DNA were selected as probes. When no unique Hind III fragment was obtained, the subclones were subjected to double digests of Hind III with EcoR I, BamH I, Bgl II, Pst $\mathrm{I}$ and Xba I.

\section{Construction of a phage library from YAC DMD 3 '-19}

A phage library was prepared from a partial Mbo I digest of DMD YAC 3'-19 and BamH I and EcoR I digested EMBL 3 vector DNA (Stratagene), according to the Stratagene protocol. Packaging was performed using freeze thaw lysate and sonic extract (Gigapack Gold II, Stratagene). The phage library was plated on P2392 host strain, and filter lifts were prepared on Hybond $\mathrm{N}^{+}$membrane (Amersham) by the manufacturer's protocol. The phage library filters were hybridized with vector left and right probes, prepared directly by PCR amplification of pBR322 sequences in pYAC4 template DNA (44) to identify the phage clones 
corresponding to the left and right ends of the YAC. The right arm phage was plaque purified and DNA was extracted (45), for subcloning and identification of non-repetitive probe fragments.

\section{Vectorette PCR}

The left end of YAC 7072 was isolated by Hind III vectorette PCR (46). The $200 \mathrm{bp}$ product was cloned into Bluescript (Stratagene) and transformed into competent XL-1 Blue cells (Stratagene), and the purified insert was used to screen the ICRF flow sorted human chromosome $X$ cosmid reference library (25), identifying 2 cosmids. One of these (cosmid 4965) was subcloned as described to yield unique probe $4965-5$.

\section{Partial digestion mapping of YACs}

Approximately $170-340 \mathrm{ng}$ total DNA was digested with $30,5,1$ and 0.1 units of Sfi I, Not I and Eag I, and 12, 1, 0.1 and 0.001 units of BssH II (New England Biolabs), in a final volume of $200 \mu \mathrm{l}$ of T4 DNA polymerase buffer (45). The reaction mixtures were preincubated at $4^{\circ} \mathrm{C}$ for $18 \mathrm{~h}$, and DNA was digested for $30 \mathrm{~min}$ at $50^{\circ} \mathrm{C}$ (Sfi I) or $37^{\circ} \mathrm{C}$ (all other enzymes). The reaction was stopped by the addition of $8 \mu \mathrm{l} 0.5 \mathrm{M}$ EDTA, pH 8.0, on ice. The digested DNA was size-fractionated in 1\% agarose gels, 0.5 $\times$ TBE, on a CHEF DR II (Bio-Rad) apparatus at $170 \mathrm{~V}$ with switch times of $25 \mathrm{~s}$ for $18 \mathrm{~h}, 60 \mathrm{~s}$ for $15 \mathrm{~h}$ and $100 \mathrm{~s}$ for $5 \mathrm{~h}$. Gels were alkali-blotted to Hybond $\mathrm{N}^{+}$membranes (Amersham), neutralized and air dried before hybridization sequentially with pBR322 left and right arm probes $(44,47)$ and the new single copy probes. Blots were washed as described above.

\section{Patients}

Twenty male patients from 18 families were studied (Table 2). Lymphocyte or lymphoblastoid cell line DNA (5 $\mu \mathrm{g}$ ) was digested with Hind III in T4 DNA polymerase buffer (45) for $18 \mathrm{~h}$ at $37^{\circ} \mathrm{C}$, size fractionated on $1 \%$ agarose gels, blotted to Hybond $\mathrm{N}+$ membranes, and hybridized and washed as described above.

\section{ACKNOWLEDGEMENTS}

We thank Hans Lehrach, Mark Ross, Sebastian Meier-Ewert, Dean Nizetic, Günther Zehetner and Christal Douglas for robot spotted YAC and cosmid filters and clone retrieval; David Barton, Marco Mächler and Georgia Chenevix-Trench for patient DNA samples; Douglas Higgs for genomic panels used to determine allele frequencies and Françoise Muscatelli for critical reading of the manuscript. Work was supported by the Imperial Cancer Research Fund, Human Frontiers Science Program, Medical Research Council and Muscular Dystrophy Group.

\section{REFERENCES}

I. Patil,S.R., Bartley,J.A., Murray,J.C., Ionasescu,V.V. and Pearson,P.L. (1985) Cytogenet. Cell Genet. 40, 720-721.

2. Weiringa,B., Hustinx, T., Scheres,J., Renner, W. and ter Haar,B. (1985) Clin. Genet. 27, 522-523.

3. Bartley,J.A., Shivanand,P., Davenport,S., Goldstein,D. and Pickens,J. (1986) J. Pediatrics 108, 189-192.

4. Dunger,D.B., Davies,K.E., Pembrey,M., Lake,B., Pearson,P., Williams,D., Whitfield,A. and Dillon,M.J.D. (1986) Lancet 1, 585-587.

5. Wilcox,D.E., Cooke,A., Colgan,J., Boyd,E., Aitken,D.A., Sinclair,L., Glascow,L., Stephenson,J.B.P. and Ferguson-Smith,M.A. (1986) Hum. Genet. 73, $175-180$.

6. Francke,U., Harper,J.F., Darras,B.T., Cowan,J.M., McCabe,E.R.B., Kohlschutter,A., Seltzer,W.K., Saito,F., Goto,J., Harpey,J.P. and Wise,J.E. (1987) Am. J. Hum. Genet. 40, 212-227.

7. Yates,J.R.W., Gillard,E.F., Cooke,A., Colgan,J.M., Evans,T.J., and Ferguson-Smith,M.A. (1987) Cytogenet. Cell Genet. 46, 723-724.

8. Chelly,J., Marlhens,F., Dutrillaux,B., Van Ommen,G.J., Lambert,M., Hajoun,B., Boissinot,G. and Fardeau,M. (1988) Hum. Genet. 78, 222-227.

9. Darras,B.T. and Francke,U. (1988) Am. J. Hum. Genet. 43, 126-130.

10. Davies,K.E., Patterson,M.N., Kenwrick,S.J., Bell,M.V., Sloan,H.R., Westman,J.A., Elsas,L.J. and Mahan,J. (1988) Am. J. Med. Genet. 29, $557-564$.

11. McCabe,E.R.B., Towbin,J., Chamberlain,J., Baumbach,L., Witkowskj,J, van Ommen,G.J.B., Koenig,M., Kunkel,L.M. and Seltzer,W.K. (1989) J. Clin. Invest. 83, 95-99.

12. Towbin,J.A., Chamberlain,J.S., Wu,D., Pillers,D.-A.M., Seltzer,W.K. and McCabe,E.R.B. (1990) Genomics 7, 442-444.

13. Davies,K.E., Mandel,J.-L., Monaco,A.P., Nussbaum,R.L. and Willard,H.F. (1991) HGM11. Cytogenet Cell Genet. 58, 853-966.
14. van Ommen,G.J.B., Verkerk,J.M.H., Hofker,M.H., Monaco,A.P. Kunkel,L.M., Ray,P., Worton,R., Wieringa,B., Bakker,E. and Pearson,P.L. (1986) Cell 47, 499-504

15. Norby,S. and Schwartz,M. (1987) Clin. Genet. 31, 192-197.

16. Bartley,J. and Gies,C. (1989) Cytogenet. Cell. Genet. 51, 958.

17. Trask,B.J., Massa, H.F. and Burmeister,M. (1992) Genomics 13, 455-457.

18. Walker,A.P., Larin,Z., Lehrach,H. and Monaco,A.P. (1991) Cytogenet. Cell Genet. 58, 2087.

19. Burmeister,M. and Lehrach,H. (1986) Nature 324, 582-585.

20. Burmeister,M., Monaco,A.P., Gillard,E.F., van Ommen,G.-J.B., Affara,N.A., Ferguson-Smith,M.A., Kunkel,L.M. and Lehrach,H. (1988) Genomics 2, $189-202$.

21. Love,D.R., Bloomfield,J.F., Kenwrick,S.J., Yates,J.R.W. and Davies,K.E. (1990) Genomics 8, 106-112.

22. Worley,K.C., Towbin,J.A., Zhu,X.M., Barker,D.F., Ballabio,A., Chamberlain,J., Biesecker,L.G., Blethen,S.L., Brosnan,P., Fox,J.E., Rizzo,W.B., Romeo,G., Sakuragawa,N., Seltzer,W.K., Yamaguchi,S. and McCabe,E.R.B. (1992) Genomics 13, 957-961.

23. Larin,Z., Monaco,A.P. and Lehrach,H. (1991) Proc. Natl. Acad. Sci. USA 88, 4123-4127

24. Monaco,A.P., Walker,A.P., Millwood,I., Larin,Z. and Lehrach,H. (1992) Genomics 12, 465-473

25. Nizetic,D., Zehetner,G., Monaco,A.P., Gellen,L., Young,B.D. and Lehrach,H. (1991) Proc. Natl. Acad. Sci. USA 88, 3233-3237.

26. Den Dunnen,J.T., Grootscholten,P.M., Bakker,E., Blonden,L.A.J., Ginjaar,H.B., Wapenaar,M.C., van Passen,H.M.B., van Broeckhoven,C., Pearson,P.L. and van Ommen,G.J.B. (1989) Am. J. Hum. Genet. 45, $835-847$.

27. Marlhens,F., Chelly,J., Kaplan,J.C., Lefrancois,D., Harpey,J.P. and Dutrillaux,B. (1987) Hum. Genet. 77, 379-383.

28. Love,D.R., Flint,T.J., Marsden,R.F., Bloomfield,J.F., Daniels,R.J., Forrest,S.M., Gabrielli,O., Giorgi,P., Novelli,G. and Davies,K.E. (1990) Am. J. Med. Genet. 37, 136-142.

29. Récan,D., Chafey,P., Leturcq,F., Hugnot,J.-P., Vincent,N., Tomé,F., Collin.H., Simon,D., Czernichow,P., Nicholson,L.V.B., Fardeau,M. and Kaplan,J.-C. (1992) J. Clin. Invest. 89, 712-716.

30. Kenwrick,S., Patterson,M., Speer,A., Fischbeck,K. and Davies,K. (1987) Cell 48, 351-357

31. Bird,A.P. (1986) Nature 321, 209-213.

32. Bartlett,R.J., Walker,A.P., Laing,N.G., Koh,J., Secore,S.L., Speer,M.C., Pericak-Vance,M.A., Hung,W.-Y., Yamaoka,L.H., Siddique,T., Kandt,R. and Roses,A.D. (1989) Lancet 1, 496-497.

33. Fisher,E.M.C., Beer-Romero,P., Brown,L.G., Ridley,A., McNeil,J.A., Bentley Lawrence,J., Willard,H.F., Bieber,F.R. and Page,D.C. (1990) Cell 63, $1205-1218$.

34. Feil,R., Aubourg,P., Mosser,J., Douar,A.-M., Le Paslier,D., Philippe,C. and Mandel,J.-L. (1991) Am. J. Hum. Genet. 49, 1361-1371

35. Kunkel,L.M. et al. (1986) Nature 322, 73-77.

36. van Ommen,G.J.B., Bertelson,C.E., Ginjaar,H.B., Den Dunnen,J.T., Bakker,E., Chelly,J., Matton,M, Van Essen,A.J., Bartley,J., Kunkel,L.M. and Pearson,P.L. (1987) Genomics 1, 329-336.

37. Feener,C.A., Koenig,M. and Kunkel,L.M. (1989) Nature 338, 509-511

38. Boyce,F.M., Beggs,A.H., Feener,C. and Kunkel,L.M. (1991) Proc. Natl. Acad. Sci. USA 88, 1276-1280.

39. Buckler,A.J., Chang,D.D., Graw,S.L., Brook,J.D., Haber,D.A., Sharp,P.A. and Housman,D.E. (1991) Proc. Natl. Acad. Sci. USA 88, $4005-4009$

40. Southem,E.N., Anand,R., Brown,W.R.A. and Fletcher,D.S. (1987) Nucleic Acids Res. 15, 5925-5943.

41. Monaco,A.P., Lam,V.M.S., Zehetner,G., Lennon,G.G., Douglas,C., Nizetic,D., Goodfellow,P.N. and Lehrach,H. (1991) Nucleic Acids Res. 19, 3315-3318.

42. Feinberg,A.P. and Vogelstein,B. (1983) Anal. Biochem. 132, 6-13.

43. Baxendale,S., Bates, G.P., MacDonald,M.E., Gusella,J.F. and Lehrach,H. (1991) Nucleic Acids Res. 19, 6651.

44. Hirst,M.C., Rack,K., Nakahori,Y., Roche,A., Bell,M.V., Flynn,G. Christadoulou,Z., MacKinnon,R.N., Francis,M., Littler,A.J., Anand,R., Poustka,A.-M., Lehrach,H., Schlessinger,D., D'Urso,M., BuckJe,V.J. and Davies,K.E. (1991) Nucleic Acids Res. 19, 3283-3288.

45. Sambrook,J., Fritsch,E.F. and Maniatis,T. (1989) Molecular Cloning: A Laboratory Manual (2nd Edition). Cold Spring Harbor Laboratory Press, Cold Spring Harbor, NY.

46. Riley,J., Butler,R., Ogilvie,D., Finniear,R., Jenner,D., Powell,S., Anand,R., Smith,J.C. and Markham,A.F. (1990) Nucleic Acids Res. 18, 2887-2890.

47. Burke,D.T., Carle,G.F. and Olson,M.V. (1987) Science 236, 806-812. 